\title{
DETERMINATION AND COMPARISON OF FATTY ACIDS COMPOSITION OF APRICOT AND PEACH OILS
}

\author{
LESIA SAVCHENKO $^{1 *}$, LIUDAS IVANAUSKAS ${ }^{2}$, LAURYNAS JARUKAS ${ }^{2}$, VICTORIYA \\ GEORGIYANTS $^{3}$
}

\author{
${ }^{I}$ Department of Quality, Standardization and Certification of Medicines, Institute of Pharmacy Professionals Qualification \\ Improvement, National University of Pharmacy, 17 Zahysnynykiv Ukrainy Sqaure, 61001, Kharkiv, Ukraine \\ ${ }^{2}$ Department of Analytical and Toxicological Chemistry, Lithuanian University of Health Sciences, 9 A. Mickevičiaus Street, \\ 44307, Kaunas, Lithuania \\ ${ }^{3}$ Department of Pharmaceutical Chemistry, National University of Pharmacy, 4 Valentynivska Street, 61000, Kharkiv, Ukraine
}

*corresponding author: savchenkolesia@gmail.com

Manuscript received: December 2020

\begin{abstract}
Apricot and peach oils are often found in pharmaceutical dosage forms. They can be purchased from different manufacturers, which use various approaches for their standardization. The main determinant of any quality oil is represented by fatty acids (FA). Therefore, determination and comparison of FA composition of these oils and assessment of their storage period influence on it were performed. FA composition was determined by gas chromatography using specific Rt-2560 column and Supelco 37 Component FAME Mix. 26 FA in apricot and 28 FA in peach oil samples were identified. Oleic $(67.21 \%$ in apricot oil; $63.29 \%$ in peach oil) and linoleic $(22.13 \%$ in apricot oil; $25.40 \%$ in peach oil) acids were characterized by the highest average concentration in both oils. Among saturated FA, palmitic acid was the first (5.87\% in apricot oil; 5.95\% in peach oil) and stearic acid was the second (2.08\% in apricot oil; $2.92 \%$ in peach oil). Total saturated fatty acids (TSFA) and total unsaturated fatty acids (TUFA) values also didn't have significant differences. The oils have close composition, despite various expiration dates and manufacturers.
\end{abstract}

\section{Rezumat}

Uleiurile de caisă și piersică se regăsesc în compoziția diferitelor forme farmaceutice. Conținutul în acizi grași (FA) reprezintă componenta dominantă a oricărui ulei esențial de calitate. În acest studiu am evaluat compoziția în acizi grași a acestor două uleiuri şi am investigat influența perioadei de stocare asupra acesteia. Compoziția în acizi grași a fost determinată prin gazcromatografie, regăsind 26 în uleiul de caise și respectiv 28 în uleiul de piersică. În concentrația cea mai mare s-au determinat acizii oleic (67,21\% în uleiul de caise și 63,29\% în uleiul de piersici) și linoleic (22,13\% în uleiul de caise şi $25,40 \%$ în uleiul de piersici). Dintre acizii grași saturați, acidul palmitic s-a regăsit în concentrația cea mai mare (2,08\% în uleiul de caise și $2,92 \%$ în uleiul de piersici), urmat fiind de acidul stearic (2,08\% în uleiul de caise și 2,92\% în uleiul de piersici). Deși uleiurile investigate aveau producători diferiți și date de expirare diferite, compoziția chimică a fost asemănătoare.

Keywords: apricot oil, peach oil, fatty acids composition, quality

\section{Introduction}

Natural fatty oils are often found among the components of many dosage forms and cosmetic products of pharmacy and factory production. Despite the fact that oils are auxiliary components in these products, they can have different pharmacological effects due to their rich FA composition. They are serving as a cosmetic base, reduce skin inflammation, and prevent water loss mainly by making a protective layer on the epidermis [13, 22].

Along with other natural fatty oils, apricot and peach oils are often found in many pharmaceutical products. Due to their anti-microbial, anti-septic, anti-oxidant, anti-ageing, anti-bacterial, and antifungal properties $[2,19,21]$, the mentioned oils are often introduced into the composition of ointments, lotions, balms, face scrubs, lip balms, creams and suspensions [2, 7, 20].

Peach oil is used more often in the preparation of dosage forms in Ukraine. At the same time, dosage forms with a similar composition are found on the pharmaceutical market, but apricot oil is often prescribed instead of peach oil. The saturated and polyunsaturated FA are responsible the oil's pharmacological effects. According to the different publications, the main FA of apricot $[1-5,7-9,14-16,18,20]$ and peach $[5,6,9,11,18]$ oils are oleic, linoleic, palmitic and stearic. Their widespread use in pharmacy and medicine is also due to the presence of linolenic acid [1, 4-9, 11 , $14-16,18,20]$. In addition to these acids, the presence of myristic [1, 3, 5, 8, 11, 15, 18, 21], arachidic [1, 5, $6,8,9,11,15,18,19,21]$, behenic $[6,8,9,18,21]$, palmitoleic $[6,11,18,21]$, lignoceric $[8,18,21]$, 
eicosanoic $[11,18,21]$ and heptadecanoic $[8,11,18$, $21]$ acids was determined in both oils. Many of them also have beneficial effects on the human skin.

For the preparation of the dosage forms, oils are purchased from completely different manufacturers. One of the main indicators of the quality of any oil is its FA composition. The main problem in establishing the quality of both apricot and peach oils is the absence of an appropriate monographs in the European Pharmacopoeia. The analysis of the quality certificates of the studied samples showed that most of them contain the results of the determination the content of basic FA, without any references to the regulatory documents. At the same time, some manufacturers specify the permissible limits of main acids content, but their values differ from each other.

Another issue encountered in different drug preparations is the preservation of their quality throughout all storage period. It is known that due to the content of unsaturated FA, oils can oxidize and rancid over time. To get answers to these questions, an experiment design was made (Figure 1). Its results will help solving the given problems.

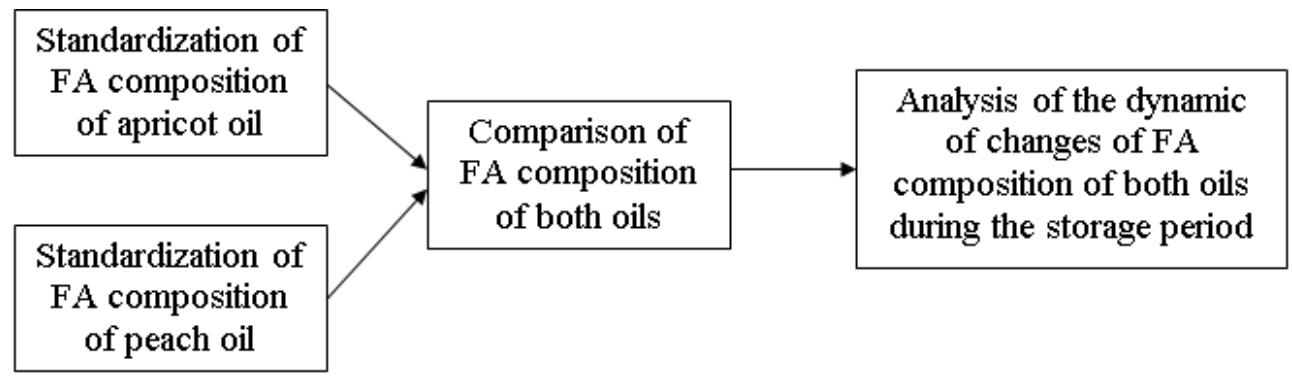

Figure 1.

Experimental design of the study

\section{Materials and Methods}

Reagents and oils samples

Supelco 37 Component FAME Mix $(1 \times 1 \mathrm{~mL}$, varied conc. in dichloromethane) and boron trifluoridemethanol $\left(\mathrm{BF}_{3} * \mathrm{CH}_{3} \mathrm{OH}\right)$ solution $(\sim 10 \%)$ for gas chromatography derivatization were purchased from Sigma-Aldrich, USA. The reagents and solvents employed for methylation and fatty acids methyl esters (FAME) extraction were also obtained from Sigma Aldrich, USA.

Different oils samples from various manufacturers were purchased for the study: four samples of apricot oil: sample № 1 produced in Great Britain (date of manufacture 02.2019); sample № 2 produced by UAB Naujoji Barmune, Lithuania (date of manufacture 06.2018); sample № 3 produced in Germany (date of manufacture 03.2018); sample № 4 produced by Harmonie \& Expression, Ukraine (date of manufacture 09.2016); six samples of peach oil: sample № 1 produced in Great Britain (date of manufacture 07.2018); sample № 2 produced in Germany (date of manufacture 04.2019); sample № 3 produced by Star Ingredients $\mathrm{GmbH}$, Germany (date of manufacture 02.2018); sample № 4 produced by Star Ingredients GmbH, Germany (date of manufacture 03.2019); sample № 5 produced by Gustav Hees $\mathrm{GmbH}$, Italy (date of manufacture 12.2017); sample № 6 produced by Harmonie \& Expression, Ukraine (date of manufacture 10.2016). The analysis of four samples of peach oil was carried out in June, 2019. The analysis of the samples № 2 and № 4 was carried out in March, 2020. All apricot oil samples were analysed in June, 2019.

\section{Sample preparation}

$0.05 \mathrm{~g}$ of the oil was weighed into a $10 \mathrm{~mL}$ vial. After that, $0.25 \mathrm{~mL}$ of the potassium hydroxide solution in methanol $60 \mathrm{~g} / \mathrm{L}$ and $1 \mathrm{~mL}$ of the $\mathrm{BF}_{3} * \mathrm{CH}_{3} \mathrm{OH}$ solution were added. The vial was tightly closed, shaken and left on a glycerine bath with a temperature of $100^{\circ} \mathrm{C}$ for 3 hours. After complete cooling of the vial, $1 \mathrm{~mL}$ of water and $1 \mathrm{~mL}$ of hexane were added, shaken for 1 minute, and allowed to settle until the layers are completely separated. A hexane layer was used for the analysis.

GC-FID method

The FA profile was determined as FAMEs by gas chromatography. The samples were analysed on a gas chromatograph GC-2010 Plus Shimadzu with a FID detector and AOC-20i+s auto sampler. The samples were separated using biscyanopropyl polysiloxane capillary Rt-2560 column (100 m x 0.25 mm ID, $0.20 \mu \mathrm{m}$ film) from Restek Corporation, USA. The injector temperature was $230^{\circ} \mathrm{C}$ and the detector temperature was $250^{\circ} \mathrm{C}$. The temperature program for the column was: initial temperature $100^{\circ} \mathrm{C}$, hold at $100^{\circ} \mathrm{C}$ for $5 \mathrm{~min}$, increase by $3^{\circ} \mathrm{C} / \mathrm{min}$ to $240^{\circ} \mathrm{C}$ and then hold at this temperature for $20 \mathrm{~min}$. Injection volume was $1.0 \mu \mathrm{L}$, injection mode was split (split ratio 1:100), carrier gas - helium.

FAMEs were identified by matching their relative and absolute retention times to Supelco FAME Mix standards. Relative concentrations of identified FA were expressed as the relative percentages of the total FA components peak area. Total peak area was calculated as the sum of all identified peaks of FA. 
FARMACIA, 2021, Vol. 69, 5

\section{Results and Discussion}

The FA profile is a main determinant of the oil quality. Therefore, the primary task of apricot and peach oils standardization was the study of their FA composition. All the samples of oils used in this study were obtained by cold pressing followed by refining. According to different researches, gas chromatography has been used extensively for the determination of FA composition in different previous studies. Different columns were used for these purposes: capillary, $25 \mathrm{~cm}$ [8]; capillary, $30 \mathrm{~m}[6,18]$; capillary, $60 \mathrm{~m}[15,20]$; capillary, $100 \mathrm{~m}$ [14]; stainless steel, $190 \mathrm{~cm} \mathrm{[3];} \mathrm{stainless} \mathrm{steel,} 244 \mathrm{~cm} \mathrm{[11].} \mathrm{Since} \mathrm{the}$ main goal of the study was to determine the presence of the maximum amount of FA in the studied samples of oils, the $100 \mathrm{~m}$ column with stationary phase selectively optimized for isomer separation to ensure accurate quantification of FAME's was used. It is commonly used only for the determination of the FA composition because it allows for the separation of FAME based on chain length and degree of unsaturation [17].

FA were converted to the corresponding methyl esters using methanol solution of potassium hydroxide and trifluoride-methanol solution $(\sim 10 \%)$ before the analysis.

The analysis allowed identifying 26 fatty acids in most apricot oil samples. Example of apricot oil chromatogram is described in Figure 2.

13 saturated fatty acids were determined among them. Despite their large number (half of the amount detected), the total concentration of saturated FA in the oils samples varies between 6.79 - 10.80\% (Table I). Most of all FA in apricot oils are monounsaturated -
7 acids $(62.80-71.98 \%)$. Polyunsaturated are in the second place -6 acids (19.06 - 26.40\%). Thus, the ratio between unsaturated and saturated FA (TUFA/ TSFA) was calculated as $8.26-13.73$. The average value was 10.49 .

Table I shows the results of the determination of the main FA content identified in apricot oil. All values are means of duplicate determinations of three samples of each oil.

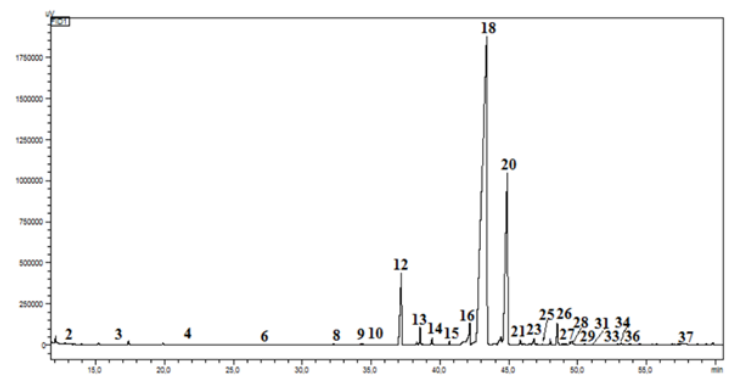

Figure 2.

Chromatogram of apricot oil (sample № 3)

2-methyl hexanoate; 3-methyl octanoate; 4-methyl decanoate; 6-methyl laurate; 8 -methyl myristate; 9 -myristoleic acid methyl ester; 10 -methyl pentadecanoate; 12 -methyl palmitate; 13-methyl palmitoleate; 14 -methyl heptadecanoate; 15 -cis10-heptadecenoic acid methyl ester; 16-methyl stearate; 18-cis-9-oleic acid methyl ester; 20 -methyl linoleate; 21-methyl arachidate; 23-methyl eicosenoate; 25-methyl heneicosanoate; 26 -cis-11,14-eicosadienoic acid methyl ester; 27-methyl behenate; 28 -cis-8,11,14-eicosatrienoic acid methyl ester; 29-methyl erucate; 31-methyl cis-5,8,11,14eicosatetraenoic acid methyl ester; 33-cis-13,16docosadienoic acid methyl ester; 34-methyl lignocerate; 36-methyl nervonate; 37-cis-4,7,10,13,16,19docosahexaenoic acid methyl ester.

Table I

Fatty acids determination results for apricot oil samples

\begin{tabular}{|c|c|c|c|c|c|}
\hline \multirow{2}{*}{$\begin{array}{c}\text { Fatty acids } \\
\text { (\% of total FA) }\end{array}$} & \multicolumn{4}{|c|}{ Number of the oil sample } & \multirow{2}{*}{ Mean } \\
\hline & № 1 & № 2 & № 3 & № 4 & \\
\hline \multicolumn{6}{|c|}{ Saturated fatty acids } \\
\hline Myristic (14:0) & 0.045 & 0.021 & 0.073 & 0.052 & 0.048 \\
\hline Palmitic (16:0) & 7.31 & 5.44 & 5.69 & 5.05 & 5.87 \\
\hline Stearic (18:0) & 2.28 & 1.07 & 2.11 & 2.86 & 2.08 \\
\hline Arachidic (20:0) & 0.31 & 0.11 & 0.19 & 0.27 & 0.22 \\
\hline Behenic (22:0) & 0.58 & 0.042 & 0.17 & 0.99 & 0.45 \\
\hline Lignoceric (24:0) & 0.23 & 0.025 & 0.025 & 0.34 & 0.16 \\
\hline Total & 10.80 & 6.79 & 8.62 & 9.65 & 8.97 \\
\hline \multicolumn{6}{|c|}{ Monounsaturated fatty acids } \\
\hline Palmitoleic (16:1) & 0.14 & 0.92 & 0.64 & 0.16 & 0.47 \\
\hline Cis-9-oleic acid (18:1) & 61.60 & 65.65 & 70.81 & 70.78 & 67.21 \\
\hline Eicosenoic (20:1) & 1.01 & 0.28 & 0.41 & 0.32 & 0.51 \\
\hline Total & 62.80 & 66.97 & 71.98 & 71.30 & 68.26 \\
\hline \multicolumn{6}{|c|}{ Polyunsaturated fatty acids } \\
\hline Linoleic (18:2) & 26.06 & 25.93 & 18.16 & 18.35 & 22.13 \\
\hline Cis-11,14-eicosadienoic acid (20:2) & 0.31 & 0.27 & 1.14 & 0.65 & 0.59 \\
\hline Total & 26.40 & 26.25 & 19.40 & 19.06 & 22.78 \\
\hline TUFA* & 89.20 & 93.22 & 91.38 & 90.36 & 91.04 \\
\hline TUFA/TSFA* & 8.26 & 13.73 & 10.60 & 9.36 & 10.49 \\
\hline
\end{tabular}

*TUFA - total unsaturated fatty acids; TUFA/TSFA - values of ratio unsaturated/saturated fatty acids 
FARMACIA, 2021, Vol. 69, 5

Since the primary task was to standardize the FA composition of the apricot oil, the average content in the test samples was calculated for each acid listed in Table I.

In all samples except those FA listed in the Table I, other saturated (hexanoic, octanoic, decanoic, lauric, pentadecanoic, heptadecanoic, heneicosanoic), monounsaturated (myristoleic, cis-10-heptadecenoic, erucic) and polyunsaturated (cis-8,11,14-eicosatrienoic, cis5,8,11,14-eicosatetraenoic and cis-4,7,10,13,16,19docosahexaenoic) FA were also found (at the concentration less than $0.05 \%$ ). Polyunsaturated cis-13,16-docosadienoic acid was found only in the sample № 3 .

Table II shows the results of determining the content of the main FA identified in samples of peach oil. All values are means of duplicate determinations of three samples of each oil. The average content in the test samples was also calculated for each acid.

The FA content in all samples is characterized by comparable values. $28 \mathrm{FA}$ were identified in most samples of peach oil. 15 saturated fatty acids, 6 monounsaturated and 7 polyunsaturated FA were among of them. Example of peach oil chromatogram is described in Figure 3.

As in apricot oil, despite a greater number of saturated FA, they represent a smaller fraction than unsaturated in percentage expression - from $8.05 \%$ to $11.67 \%$ in different samples. The same as in apricot oil, the concentration of monounsaturated FA in peach oil is the highest $(56.71-69.70 \%)$. Polyunsaturated fatty acids are at the second place - $22.23-31.62 \%$. The ratio between unsaturated and saturated (TUFA/ TSFA) FA was calculated as 7.57 - 11.42.

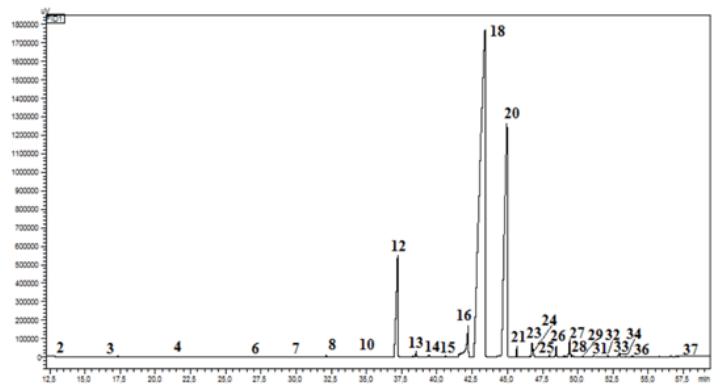

Figure 3.

Chromatogram of peach oil (sample № 1)

2-methyl hexanoate; 3-methyl octanoate; 4-methyl decanoate; 6-methyl laurate; 7 - methyl tridecanoate; 8 -methyl myristate; 10-methyl pentadecanoate; 12-methyl palmitate; 13-methyl palmitoleate; 14-methyl heptadecanoate; 15 -cis-10-heptadecenoic acid methyl ester; 16 -methyl stearate; 18 -cis-9oleic acid methyl ester; 20 -methyl linoleate; 21 -methyl arachidate; 23-methyl eicosenoate; 24-methyl linolenate 25-methyl heneicosanoate; 26-cis-11,14-eicosadienoic acid methyl ester; 27 -methyl behenate; 28 -cis-8,11,14eicosatrienoic acid methyl ester; 29 -methyl erucate; 31 methyl cis-5,8,11,14-eicosatetraenoic acid methyl ester; 32-methyl tricosanoate; 33-cis-13,16-docosadienoic acid methyl ester; 34-methyl lignocerate; 36-methyl nervonate; 37-cis-4,7,10,13,16,19-docosahexaenoic acid methyl ester.

Table II

Fatty acids determination results for peach oil samples

\begin{tabular}{|c|c|c|c|c|c|c|c|}
\hline \multirow{2}{*}{$\begin{array}{c}\text { Fatty acids } \\
\text { (\% of total FA) }\end{array}$} & \multicolumn{6}{|c|}{ Number of the oil sample } & \multirow{2}{*}{$\begin{array}{c}\text { Average } \\
\text { value }\end{array}$} \\
\hline & № 1 & № 2 & № 3 & № 4 & № 5 & № 6 & \\
\hline \multicolumn{8}{|c|}{ Saturated fatty acids } \\
\hline Myristic (14:0) & 0.045 & 0.049 & 0.069 & 0.078 & 0.097 & 0.055 & 0.066 \\
\hline Palmitic (16:0) & 6.66 & 5.04 & 6.57 & 6.73 & 5.37 & 5.30 & 5.95 \\
\hline Stearic (18:0) & 2.60 & 2.97 & 3.53 & 3.34 & 2.09 & 2.99 & 2.92 \\
\hline Arachidic (20:0) & 0.31 & 0.25 & 0.24 & 0.23 & 0.18 & 0.26 & 0.25 \\
\hline Behenic (22:0) & 0.72 & 0.78 & 0.86 & 0.71 & 0.17 & 0.88 & 0.69 \\
\hline Lignoceric (24:0) & 0.27 & 0.27 & 0.28 & 0.22 & 0.022 & 0.31 & 0.23 \\
\hline Total & 10.67 & 9.45 & 11.67 & 11.38 & 8.05 & 9.86 & 10.18 \\
\hline \multicolumn{8}{|c|}{ Monounsaturated fatty acids } \\
\hline Palmitoleic (16:1) & 0.15 & 0.13 & 0.085 & 0.11 & 0.56 & 0.14 & 0.20 \\
\hline Cis-9-oleic acid (18:1) & 64.16 & 64.21 & 56.35 & 62.44 & 68.63 & 63.97 & 63.29 \\
\hline Eicosenoic $(20: 1)$ & 0.40 & 0.34 & 0.23 & 0.21 & 0.39 & 0.52 & 0.35 \\
\hline Total & 64.78 & 64.77 & 56.71 & 62.79 & 69.70 & 64.67 & 63.90 \\
\hline \multicolumn{8}{|c|}{ Polyunsaturated fatty acids } \\
\hline Linoleic (18:2) & 23.90 & 25.28 & 31.11 & 25.53 & 21.85 & 24.74 & 25.40 \\
\hline Linolenic (18:3) & 0.15 & - & - & - & - & 0.26 & 0.21 \\
\hline Cis-11,14-eicosadienoic acid (20:2) & 0.40 & 0.33 & 0.16 & 0.10 & 0.22 & 0.32 & 0.26 \\
\hline Cis-4,7,10,13,16,19-docosahexaenoic acid (22:6) & 0.032 & 0.12 & 0.27 & 0.12 & 0.11 & 0.075 & 0.12 \\
\hline Total & 24.54 & 25.79 & 31.62 & 25.83 & 22.23 & 25.47 & 25.91 \\
\hline TUFA* & 89.32 & 90.56 & 88.33 & 88.61 & 91.94 & 90.15 & 89.82 \\
\hline TUFA/TSFA* & 8.37 & 9.58 & 7.57 & 7.79 & 11.42 & 9.14 & 8.98 \\
\hline
\end{tabular}

*TUFA - total unsaturated fatty acids; TUFA/TSFA - values of ratio unsaturated/saturated fatty acids.

Saturated (hexanoic, octanoic, decanoic, lauric, pentadecanoic, heptadecanoic, heneicosanoic), mono- unsaturated (cis-10-heptadecenoic, erucic, nervonic) and polyunsaturated (cis-8,11,14-eicosatrienoic, cis- 
5,8,11,14-eicosatetraenoic, cis-13,16-docosadienoic) acids were also found (at the concentration less than $0.05 \%$ ) in all samples of peach oil except those listed in Table II. Saturated tridecanoic acid was found in the samples № 1-4 and tricosanoic acid - in the samples № 1 and № 5. Monounsaturated myristoleic acid was found only in the sample № 5 .

According to the published data, the composition of apricot and peach oils is similar, so it was interesting to compare the average content of basic FA in both oils obtained after the conducted analysis. The analysis of all samples has shown the presence of a high content of unsaturated FA. The highest concentration in both apricot and peach oil is characterized by monounsaturated oleic (mean value apricot oil $=67.21 \%$; mean value $_{\text {peach oil }}=63.29 \%$ ) and polyunsaturated linoleic acid (mean value apricot oil $=22.13 \%$; mean value $e_{\text {peach oil }}=$ $25.40 \%)$.

The major saturated fatty acid was palmitic (mean value $_{\text {apricot oil }}=5.87 \%$; mean value peach oil $=5.95 \%$ ) followed by stearic acid (mean value apricot oil $=2.08 \%$; mean value peach oil $=2.92 \%$ ) both in apricot and peach oil (Tables I and II). Behenic and arachidic acids are characterized by lower concentration $(<1 \%)$.

The results indicate a little bit lower concentration of oleic acid and a slightly higher content of linoleic acid in peach oil samples, while the concentrations of palmitic and stearic acids are very close in both oil samples.

Among the monounsaturated FA, minor to trace amounts of palmitoleic, eicosenoic, cis-10-heptadecenoic, erucic and myristoleic acids were also found in both oils (Tables I and II). The difference is only in palmitoleic and eicosenoic acids concentration (in peach oil

samples concentration of eicosenoic acid was higher than the palmitoleic acid -0.35 and $0.20 \%$ respectively). In addition, nervonic acid was found in peach oil samples and was not identified in apricot oil samples. Among polyunsaturated acids cis-11,14-eicosadienoic, cis-8,11,14-eicosatrienoic， cis-5,8,11,14-eicosatetraenoic, cis-4,7,10,13,16,19-docosahexaenoic and cis13,16-docosadienoic acids were found in apricot oil after the linoleic acid. As for the composition of these acids, peach oil differs only in the presence of a small amount of linolenic acid (mean value $=0.21 \%$ ) in the samples № 1 and № 5. It ranks the second place in concentration among polyunsaturated fatty acids in these samples.

Regarding the total amount of FA, small quantities of tridecanoic and tricosanoic acids were also found in peach oil samples. They were not found in apricot oil samples. It should also be noted that the ratio TSFA (mean value apricot oil $=8.97$; mean value peach oil $=$ 10.18 ) and TUFA (mean value apricot oil $=91.04$; mean value $_{\text {peach oil }}=89.82$ ) in samples of both oils is quite similar. This fact additionally indicates their close FA composition.

The independent-samples t-test was done (Table III) for determining the statistical significance of differences between FA composition of apricot and peach oil samples. The Student's coefficient ( $\mathrm{T}$ value) was calculated for each FA founded in both oils FA with total value of standard deviation using. The Student's distribution table gives a critical value of $\mathrm{T}(95 \% ; 8)=2.31 \%$ for a risk of $5 \%(\alpha=0.05)$. The calculated $\mathrm{T}$ value for all FA is less than $2.31 \%$, so the differences between FA composition of apricot and peach oils are not statistically significant $(p>0.05)$.

Table III

Statistical data for differences between apricot and peach oil samples determination

\begin{tabular}{|l|c|c|c|c|c|}
\hline \multicolumn{1}{|c|}{ Fatty acid } & $\boldsymbol{S D}_{\text {tot }}$ & $\boldsymbol{T}$ value, $\%$ & Fatty acid & $\boldsymbol{S D}_{\text {tot }}$ & $\boldsymbol{T}$ value, \% \\
\hline Myristic & 0.0004 & 1.35 & Palmitoleic & 0.0748 & 1.53 \\
\hline Palmitic & 0.7559 & 0.13 & Cis-9-oleic acid & 17.3847 & 1.46 \\
\hline Stearic & 0.3771 & 2.12 & Eicosenoic & 0.0520 & 1.06 \\
\hline Arachidic & 0.0041 & 0.61 & Linoleic & 13.4822 & 1.38 \\
\hline Behenic & 0.1123 & 1.12 & \multirow{2}{*}{ Cis-11,14-eicosadienoic acid } & \multirow{2}{*}{0.0690} & \multirow{2}{*}{1.99} \\
\hline Lignoceric & 0.0161 & 0.90 & & & \\
\cline { 1 - 2 }
\end{tabular}

Pharmacies and factories can use the purchased fatty oils for the dosage forms preparation during the whole expiration date specified in the certificate of their quality. The quality certificates of peach and apricot oils used in the current research has shown that the oils expiration dates presented some differences. In most cases, the expiration dates was 2 years for both oils. The oils produced in Ukraine have a shelf life of 3 years. At the same time, the oils produced in Germany - only 1 year and 3 months. Since oils contain unsaturated FA and do not contain preservatives, they are able to oxidize during storage period [10, 12]. Of course, different manufacturers can use different raw materials for fatty oil production. The FA composition of the oils will be affected by the area where apricot or peach fruits are growing, soil type, geographical location and seasonal variation. However, if we analyse other monographs on fatty oils of the European Pharmacopoeia, for example, on Sunflower or Olive oil, in the subsection composition of the FA fraction of the oil, the concentration of each individual fatty acid is indicated in the digital range, which allows some variability in their content. Based on this, the analysis of the dependence of the FA composition of both oils from their shelf life was made.

The analysis of the results of the FA content in four samples of apricot oil indicates their fairly close 
FARMACIA, 2021, Vol. 69, 5

composition. The shortest storage period (3 months) at the time of the analysis has the sample of apricot oil № 1 (Table I). It contains the least amount of oleic acid and the highest amount of linoleic acid. The sample № 4 with the longest storage period (32 months) is almost comparable in concentration of both acids with the sample № 3, which has 14 months storage time. There is no clearly expressed significant change in concentration of other basic acids in apricot oil samples depending on its storage period. Differences in the concentration of FA in different oil samples cannot be called significant and their values are close to the average concentration of each FA in oil (Table I). Also, if we take into account the values of TSFA and TUFA in the samples № 1 and № 4, which have a significant difference in the periods of storage before the analysis, there are no significant distinctions between them.

Comparison of the FA concentrations in three samples (№ 1-№ 3) of peach oil with 11 months storage period indicates a slight difference in their values (Table II). The concentration of main FA in the sample № 6 with the longest storage period (31 months) is comparable with their concentration in the samples № 1 - № 3. The concentration of basic FA is slightly different from the calculated average values (for example, oleic acid concentration is $63.97 \%$ and an average value is $63.29 \%$ and linoleic acids concentration is $24.74 \%$ against mean value $25.40 \%$ ).

The same as in apricot oil, the TSFA and TUFA values are very similar in all peach oil samples, regardless of their storage period before the analysis.

Thus, it can be concluded that the oils are sufficiently stable under proper storage conditions. This fact can be explained by a high concentration of oleic acid in them. It is known that such oils are more stable than others are. Oleic acid is less susceptible to the oxidation than polyunsaturated FA from the $n-6$ series (linoleic acid) $[14,21]$. In addition, both oils are characterized by a high concentration of unsaturated FA. They are very important for the stability of oils as well for providing information for a longer shelf life [7, 21].

\section{Conclusions}

Thus, the analysis of the FA composition of apricot and peach oils indicates a close percentage content of all identified FA. Oleic acid is characterized by the highest concentration in both oils with the mean concentration in apricot oil $67.21 \%$ and in peach oil $63.29 \%$. Due to the presence of the high concentrations of oleic acid in both oils, they are characterized by a sufficiently high stability of the FA composition independently of the period of storage. A comparative characteristic of the FA percentage in the each oil samples showed the absence of significant changes in the composition of FA, regardless of their storage period and different manufacturers.

\section{Conflict of interest}

The authors declare no conflict of interest.

\section{References}

1. Alpaslan M, Hayta M, Apricot kernel: physical and chemical properties. J Am Oil Chem Soc., 2006; 82: 469-471.

2. Apricot kernel oil: risk profile, CAS No. 72869-69-3, www.mattilsynet.no.

3. Bachheti RK, Rai I, Joshi A, Rana V, Physico-chemical study of seed oil of Prunus armeniaca L. grown in Garhwal region (India) and its comparison with some conventional food oils. Int Food Res J., 2012; 19(2): 577-581.

4. Beyer R, Melton LD, Composition of New Zealand apricot kernels. New Zealand J Crop and Horticult Sci., 1990; 18: 39-42.

5. Burnett CL, Fiume MM, Bergfeld WF, Belsito DV, Hill RA, Klaassen CD, Liebler D, Marks JG, Shank RC, Slaga TJ, Snyder PW, Andersen FA, Safety assessment of plant-derived fatty acid oils. Int $J$ Toxicol., 2017; 36(3): 51S-129S.

6. Chamlia D, Bootelloa MA, Boualib I, Jouhrib S, Boukhchinab S, Martínez-Forcea E, Chemical characterization and thermal properties of kernel oils from Tunisian peach and nectarine varieties of Prunus persica. Grasas y Aceites, 2017; 68(3): e211: 1-9.

7. Gupta A, Sharma PC, Tilakratne BMCS, Verma AK, Studies on physico-chemical characteristics and fatty acid composition of wild apricot (Prunus armeniaca Linn.) kernel oil. Indian J Nat Prod Resour., 2012; 3(3): 366-370.

8. Kaya C, Kola O, Ozer MS, Altan A, Some characteristics and fatty acids composition of wild apricot (Prunus pseudoarmeniaca L.) kernel oil. Asian J Chem., 2008; 20(4): 2597-2602.

9. Kikalishvili BIu, Zurabashvili DZ, Turabelidze DG, Shanidze LA, Nikolaĭshvili MN, The fatty acid composition of peach oil and its biological activity. Georgian Med News, 2013; 218: 82-85.

10. Lautenschlager H, Essential fatty acids - cosmetic from inside and outside. Beauty Forum, 2003; 4: 54-56.

11. Lazos ES, Composition and oil characteristics of apricot, peach and cherry kernel. Grasas y Aceites, 1991; 42(2): 127-131.

12. Ligęza M, Wyglądacz D, Tobiasz A, Jaworecka K, Reich A, Natural cold pressed oils as cosmetic products. Fam Med Primary Care Rev., 2016; 18(4): 443-447.

13. Mank V, Polonska T, Use of natural oils as bioactive ingredients of cosmetic products. Ukr Food J., 2016; 5(2): 281-289.

14. Manzoor M, Anwar F, Ashraf M, Alkharfy KM, Physico-chemical characteristics of seed oils extracted from different apricot (Prunus armeniaca L.) varieties from Pakistan. Grasas y Aceites, 2012; 63(2): 193-201.

15. Orhan I, Koca U, Aslan S, Kartal M, Kusmenoglu S, Fatty acid analysis of some Turkish apricot seed oils by GC and GC-MS techniques. Turk J Pharm Sci., 2008; 5(1): 29-34. 
16. Ozkal SG, Yener ME, Bayindirli L, The solubility of apricot kernel oil in supercritical carbon dioxide. Int J Food Sci Technol., 2006; 41: 399-404.

17. Robust Analysis of Fatty Acids in Milk: An Independent Lifetime Evaluation of Rt-2560 GC Columns, https://www.restek.com.

18. Schinas P, Zannikos F, Anastopoulos G, Karonis D, Voulgaraki S, Gourniezaki A, Zannikou Y, Kalligeros $\mathrm{S}$, Converting apricot seed oil (Prunus armeniaca) and peach seed oil (Prunus persica) into biodiesel. SF J Biofuel Bioenerg., 2017; 1: 1: 1-9.

19. Sharma A, Vaidya D, Gupta A, Kaushal M, Formulation and evaluation of wild apricot kernel oil based massage cream. J Pharmacogn Phytochem., 2019; 8(1): 10171021.
20. Stryjecka M, Kiełtyka-Dadasiewicz A, Michalak M, Rachoń L, Głowacka A, Chemical composition and antioxidant properties of oils from the seeds of five apricot (Prunus armeniaca L.) cultivars. J Oleo Sci., 2019; 68(8): 729-738.

21. Wu H, Shi J, Xue S, Kakuda Y, Wang D, Jiang Y, Ye X, Li Y, Subramanian J, Essential oil extracted from peach (Prunus persica) kernel and its physicochemical and antioxidant properties. LWT - Food Sci Technol., 2011; 44(10): 2032-2039.

22. Zielinska A, Nowak I, Fatty acids in vegetable oils and their importance in cosmetic industry. Chemik, 2014; 2: 107-110. 